\title{
Telecare for the elderly: coercion, confidence and satisfaction associated with its use
}

Bruna Borba Neves'

José Roberto Goldim,2
Abstract

Objective: to evaluate the expression of coercion, confidence and satisfaction with the use of telecare. Method: a cross-sectional study was carried out of prevalent cases with elderly residents in the city of Porto Alegre, Rio Grande do Sul, Brazil, who had already used telecare services. The sociodemographic variables used were: gender, age, schooling and marital status. In order to evaluate the perception of coercion, the Perceived Coercion Scale was applied in relation to the use of telecare and those responsible for deciding to use the technology. Confidence in the use of telecare technology and the satisfaction associated with its use were evaluated. Quantitative data analysis was performed using descriptive and inferential statistical measures. Means and standard deviations were used. Differences were assessed by analysis of variance, with a significance level of $5 \%$ $(p<0.05)$. Results: the sample consisted of 25 elderly people who used telecare. When evaluating the distribution of the answers obtained, it was found that 11 (44\%) of those interviewed did not perceive any coercion associated with their decision. The others had varying perceptions, with an average of $23 \%$. Respondents expressed high confidence and satisfaction with telecare. Conclusion: the decision-making process associated with the use of telecare had a low perception of coercion, combined with high confidence and satisfaction with the use of the technology.

Pontifícia Universidade Católica do Rio Grande do Sul, Instituto de Geriatria e Gerontologia, Programa de Pós-graduação em Gerontologia Biomédica. Porto Alegre, Rio Grande do Sul, Brasil.

2 Universidade Federal do Rio Grande do Sul, Hospital de Clínicas de Porto Alegre, Serviço de Bioética. Porto Alegre, Rio Grande do Sul, Brasil.

Funding: Medical Foundation of Rio Grande do Sul, Hospital da Clinicas de Porto Alegre - Rio Grande do Sul, Bioethics and Ethics Research Lab (LAPEBEC). Process no 1799-X.

Correspondence

Bruna Borba Neves

brunanevesto@hotmail.com
Keywords: Elder. Self-Help Devices. Coercion. 


\section{INTRODUCTION}

According to demographic data the worldwide elderly population is growing. This fact has led to considerable reflection and discussion, as old age results in physical, biological, psychological and social changes in the profile of the individual and the population itself ${ }^{1}$. Because of these changes, health systems in most countries are facing significant challenges. An example of this is the need for greater efficiency, quality and equity in health services, as well as the increased demand for health care in the patient's own home. Telecare has been developed, at least in part, due to the difficulty and cost associated with hiring staff to provide health and home care services ${ }^{2}$.

Telecare is a functional and accessible form of technology, developed to meet the demand for the long-term care of the elderly ${ }^{3}$. This remote care technology consists of the use of home-installed equipment such as telephones and fall detectors that allow direct communication with a service center in the event of an emergency. This center assesses the type and severity of the situation to take appropriate measures to provide the necessary help to the user ${ }^{4}$.

The use of this technology should not be considered a form of restriction on the autonomy of the elderly. On the contrary, it may allow them to feel safe to remain in their own home. Autonomy is a key factor for a good quality of life and a necessary skill of an appropriate decision-making process. Autonomy allows a more satisfactory life, as it allows the individual to maintain control of their own life and their independence ${ }^{5}$.

However, old age is full of prejudices and stereotypes, which influence the care aimed at the elderly. Autonomy is poorly evaluated and it seems natural that care is the responsibility of family members, who may feel empowered to decide, guide, provide and manage the life of the elderly ${ }^{6}$. An overprotective family environment, where caregivers assume all the activities of the elderly for themselves, can lead to learned dependence, discouraging the elderly from exercising their autonomy ${ }^{7}$.

In many situations of daily living, it can be seen that even health professionals underestimate the decision-making capacity of the elderly, providing superficial information about their treatment and diagnosis, which may impair the freedom of individuals to decide what they consider best for their care ${ }^{8}$. They are therefore able to coerce the elderly into making decisions that do not agree with their life and health.

The coercion is defined by Piaget as: "Any relation between two or more individuals in which an element of authority or prestige intervenes." Yet, according to the same author, coercion "exists to the extent that it is suffered, (...) regardless of the actual degree of reciprocity"'.

In this context, the increasing use of new technologies in the care and monitoring of the elderly has raised questions about the effective participation and respect for the self-determination of the individuals involved. The evaluation of the degree of coercion perceived in the decision-making process and the degree of confidence and satisfaction about the use or non-use of these new assistive technologies can generate the possibility of assessing to what extent self-determination is preserved.

Thus, the objective of the present article was to evaluate the expression of coercion, confidence and satisfaction with the use of telecare of a group of elderly people who used this technology in Porto Alegre, Rio Grande do Sul, Brazil.

\section{METHOD}

A cross-sectional study of the prevalent case type was performed. The population studied was composed of elderly residents of the city of Porto Alegre (Rio Grande do Sul) who used telecare technology as clients of the company TecnoSenior, through its partner company IrisSenior. Contact was made with these two companies, and permission was asked to register their clients that already used the technology and that met the eligibility criteria of the research. The inclusion criteria were to be elderly, that is, a person aged 60 or over, and be already using telecare technology. The exclusion criterion of finding it impossible to understand participation in the research or the completion of the instrument as also applied.

The telecare companies provided the contact information of 73 elderly people and contact with potential participants was carried out by telephone. 
Eighteen elderly people were not located. Thus, contact was made with the remaining 55 elderly, and $25(45.45 \%)$ agreed to participate in the study
(Figure 1). The research was carried out at the home of the elderly person by the researcher herself and a single evaluator.

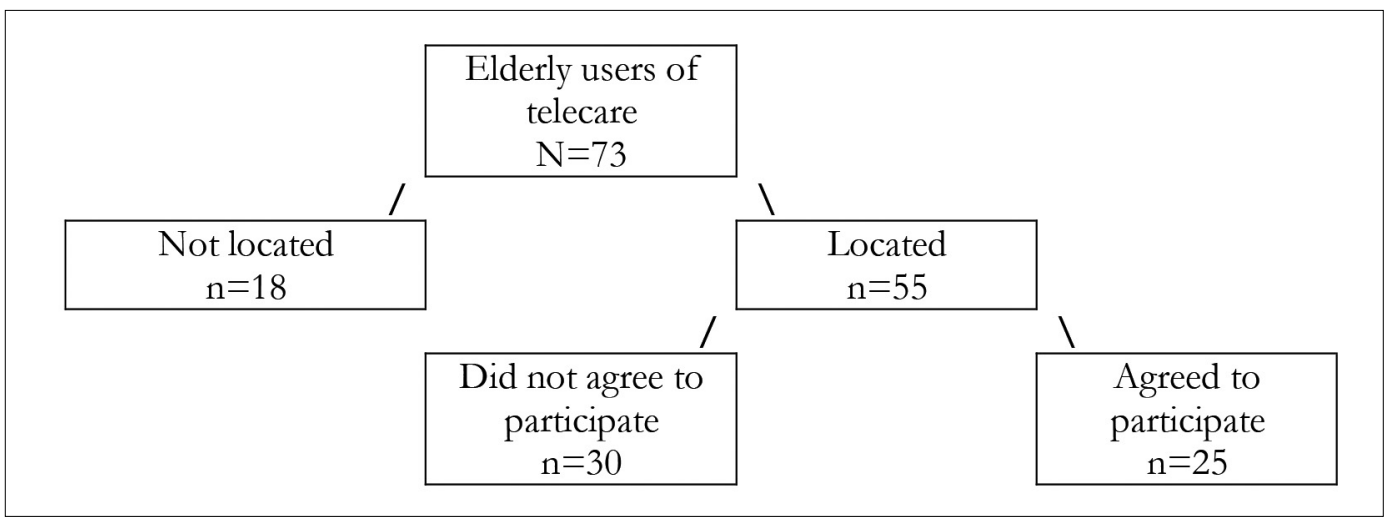

Figure 1. Flowchart of selection process of sample.

The sociodemographic variables used were: gender, age, schooling and marital status. To evaluate the perception of coercion, the Coercion Perception Scale was used in relation to the use of telecare with the question: "Who was responsible for making the decision to use this technology?". Confidence in the use of assistive technology and the satisfaction associated with its use were evaluated. These variables were obtained through visual analogue scales varying between $0 \%$ and $100 \%$. The participant marked their perception in a range between these values, without any intermediate delimiter in a line $10 \mathrm{~cm}$ long, starting at 5\% and ending at $100 \%$.

The Coercion Perception Scale is derived from a scale for assessing coercion in psychiatric hospitalization, the MacArthur Admission Experience Survey, which is composed of 16 questions $^{10}$. This instrument was developed by the MacArthur Coercion Study and validated for the Portuguese language spoken in Brazil by Taborda ${ }^{11}$.

The Coercion Perception Scale, already translated and validated for Portuguese spoken in Brazil, was adapted for the use of telecare in the present study. This scale is composed of four sentences in which the participant must indicate whether they agree or disagree. The first two affirmations indicate a lack of associated coercion, that is, those who disagree demonstrate that there was a perception of coercion associated with the reported situation. In the last two questions, the reverse occurs as affirmative responses show a perception of coercion. The first question refers to the fact that the interviewee had sufficient opportunity to say if they wanted to use assistive technology. The second question concerns the opportunity to say what they wanted about the use of assistive technology. The third question concerns the fact that no one seemed interested in whether the participant wanted to use assistive technology. The last question concerns the fact that the participant's opinion on the use of assistive technology was not asked. An open question about who was in charge of the decision to use the technology was also added to the scale.

The instrument is self-applicable and in each response the participant chooses to indicate whether they agree or disagree. The responses can vary from 0 to 4 points, 0 representing the absence of coercion and 4 a perception of maximum coercion. In order to facilitate the understanding of the results of the sample as a whole, the four point scale was transferred into a percentage value. Thus, 0 point corresponds to $0 \%$ and 4 points correspond to a $100 \%$ perception of coercion. 
Coercion can also be accompanied by individual responses to each of the issues, which assess the various perspectives of the decision-making process.

Data collection took place between December 2016 and March 2017. Data analysis was quantitative using descriptive and inferential statistical measures. Means and standard deviations were used. The differences were evaluated by analysis of variance, with a significance level of 5\% $(p<0.05)$.

The study was approved by the Scientific Commission of the Institute of Geriatrics and Gerontology (IGG) and by the Research Ethics Committee of the Pontifícia Universidade Católica do Rio Grande do Sul (PUCRS) under no 105166/2016. All the participants signed a Free and Informed Consent Form (FICF).

\section{RESULTS}

The sample consisted of 25 elderly individuals who had used telecare before the data collection. The mean age of the group was 82.24 years, ranging from 60 to 94 years. In the sample, $23(92 \%)$ were female and only two $(8 \%)$ were male. The majority of the participants, 15 (60\%), were widowed. The average schooling was 13.58 years of study and the mode and median were 12 years (Table 1 ).

Of the elderly, the majority reported living alone $(n=21 ; 84 \%)$ while only four $(16 \%)$ described living with someone, which included a husband or wife, children and/or grandchildren.

The mean of the Coercion Perception Scale was $23 \%$ (+24), ranging from $0 \%$ to $75 \%$. No participant exhibited a $100 \%$ perception of coercion in relation to telecare.

Most of the participants, 23 of the 25 elderly persons, reported having had the opportunity to say if they wanted to use telecare. Likewise, 21 of the 25 participants reported having had the opportunity to say what they wanted regarding the use of technology. The interest in knowing if the participant wanted to use this device provided more balanced answers, with 11 participants affirming that such interest existed and 14 not having this perception. Most of the participants, 19 of the 25 elderly persons, believed that their opinion was considered in the decision-making process about whether to use the technology (Figure 2).

Table 1. Sociodemographic data of users of telecare.

\begin{tabular}{lll}
\hline Sociodemographic data & $\mathrm{n}(\%)$ & Mean and standard-deviation \\
\hline Gender & $23(92)$ & \\
Female & $2(8)$ & $82.24( \pm 6.71)$ \\
Male & & \\
Age (in years) & $1(4)$ & \\
$60 \mid---70$ & $6(24)$ & $13.58( \pm 6.98)$ \\
$70 \mid---80$ & $16(64)$ & \\
$80 \mid---90$ & $2(8)$ & \\
$90 \mid---100$ & & \\
Schooling (in years) & $3(12)$ & \\
$1 \mid---8$ & $10(40)$ & \\
$9 \mid---12$ & $12(48)$ & \\
$<12$ & $3(12)$ & \\
Marital status & $7(28)$ & \\
Married & $15(60)$ & \\
Single/Separated & & \\
Widowed & & \\
\hline
\end{tabular}




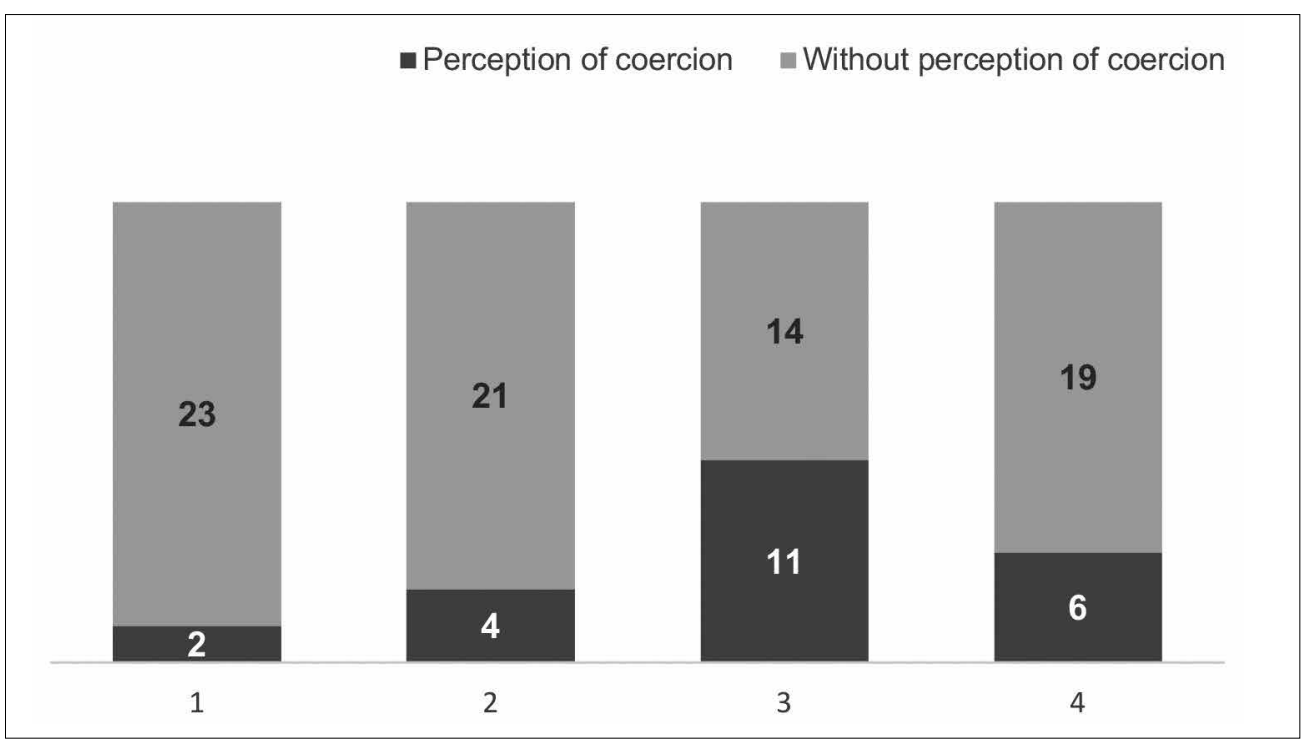

Questions of Coercion Perception Scale:

1- did you have sufficient opportunity to say that you wished to use the technology;

2- did you have the opportunity to say what you wanted to say regarding its use;

3 - was there interest in knowing if the participant wanted to use the technology;

4- was the opinion of the participant considered in the decision making process.

Figure 2. Individual responses to the four questions of the MacArthur Scale for Coercion Perception Assessment associated with the use of telecare technology $(\mathrm{N}=25)$.

When questioned about who was responsible for decision making, 12 (48\%) elderly persons said they themselves were, $11(44 \%)$ answered that their children were, one (4\%) reported that a friend was and another (4\%) said that their doctor had decided.

It is important to point out that the values of the perception of coercion obtained varied according to who made the decision, with difference results if it was a family member, a friend, a doctor or the elderly person themselves who made the decision to use the technology. The highest mean coercion value was observed when someone outside the family a doctor or a friend - made the decision $[\mathrm{M}=1.50$ $(+0.71)]$. When the decision was taken by relatives the average value was $1.18(+1.08)$. Finally, the lowest mean coercion value was observed when the person interviewed took the decision $[\mathrm{M}=0.58(+0.79)]$ (Table 2). There was no significant difference between the means for all the decision-making situations $(\mathrm{p}>0.05)$.

Table 2. Results regarding the decision maker in using telecare in relation to perceived coercion, confidence and satisfaction.

\begin{tabular}{llll}
\hline Responsible for decision to use telecare & $\begin{array}{l}\text { Perception of coercion } \\
\text { Mean (sd) }\end{array}$ & $\begin{array}{l}\text { Confidence in technology } \\
\text { Mean (sd) }\end{array}$ & $\begin{array}{l}\text { Satisfaction with use } \\
\text { Mean }(\text { sd) }\end{array}$ \\
\hline User themselves & $0.58( \pm 0.79)$ & $83.92( \pm 19.88)$ & $84.58( \pm 28.41)$ \\
Family members & $1.18( \pm 1.08)$ & $84.04( \pm 19.39)$ & $84.82( \pm 15.29)$ \\
\hline Someone outside family (doctor or friend) & $1.50 \pm( \pm 0.71)$ & $54.00( \pm 65.05)$ & $32.00( \pm 31.11)$ \\
\hline
\end{tabular}

$\mathrm{sd}=$ standard-deviation. 
A comparison of trust and satisfaction with use was made, and who played the biggest role in making the decision to use technology. The comparisons between the averages obtained with the users themselves or with relatives were not significant $(\mathrm{p}>0.05)$. It was not possible to make this comparison with the group outside the family as it only had two people.

\section{DISCUSSION}

The sample of the present study consisted of 25 elderly individuals, with a mean age of 82.24 years, ranging from 60 to 94 years. This sample is in line with other demographic data, which shows a global increase in the elderly population. These data also show an increase in the percentage of elderly people aged over 80 years old ${ }^{1}$.

The majority of study participants were women, with a frequency of $92 \%$. This proportion is higher than that observed in the general population, where women make up $50.4 \%$. This increase in female participation in the sample using telecare may be due to the fact that women are more likely to seek health services and health care options and safety measures, with higher rates of adherence to prevention programs and the use of technologies?.

The proportion of widows $(60 \%)$ in this study agrees with the values described in other studies, which show data ranging from $60 \%$ to $70 \% 0^{1,10}$.

Regarding the schooling of the participants, the average was 13.58 years of study. This value is higher than that observed in the wider Brazilian population, which is 7.8 years ${ }^{11}$.

The proportion of individuals living alone in the present study was $84 \%$, a result also found in another study, which may reflect the fact that the option to live alone can be through personal choice and also be a temporary stage in the life cycle of the individual. In addition, the proportion of people living alone is greater among older Brazilian elderly persons than younger elderly individuals, and this difference has grown over time ${ }^{10}$. In addition, people living alone are more likely to adopt telecare.
It is possible that living alone and using telecare are due to a relatively strong need for some kind of support compared to people who live with a partner or relative ${ }^{3}$. Since autonomy is the ability to control, handle and make personal decisions about how to live according to one's own rules, it can be altered by biological changes, functional incapacity, the loss of physical competence and economic factors, or other negative stereotypes associated with old age and social relations or social networks ${ }^{12}$.

Thus, we understand the importance of studying decision-making regarding well-being in the aging process, as it is affected by significant events, such as retirement, health problems and the loss of loved ones ${ }^{13}$. Making a decision involves several skills such as being able to engage with the subject, understanding or evaluating the type of alternative between the various options and communicating one's preference while knowing the risks involved. These abilities are linked directly to the ability to exercise autonomy and to determine and execute one's own desires ${ }^{14,15}$. All these characteristics were present in the participants of this study.

The elderly persons were primarily responsible for making the decision to use telecare, with a frequency of $48 \%$. Old age involves the necessity of making difficult choices, often related to the elderly's own health and the processes that may occur. The participation of the elderly in this process should not simply be the granting of assent or the delegation of the decision ${ }^{16}$.

In another group within the sample (44\%), relatives were responsible for making the decision to use telecare. Other studies have shown that the social network, represented by relatives, people close to the elderly person or caregivers, are those the elderly can rely on when deciding something or to whom they can delegate decision-making ${ }^{17}$.

Autonomy can be one of the fundamental factors for a good quality of life and is a basic need in decision making, allowing a more satisfactory life, accompanied by the preservation of the capacity to maintain the making of choices during one's life trajectory and independence ${ }^{18}$ 
The understanding that the elderly should participate in the decision-making process based on their self-determination allows us to identify that elderly persons present themselves as the main actor in the process. It is therefore important that health actions are discussed not only for such individuals but with them, so that autonomy is preserved and allowed to grow. The quest for the right to act independently, which can be demonstrated by the confidence and satisfaction associated with the use of telecare, can enable a healthy and pleasant longevity for the aging population $^{19}$.

The limitations of the present study included the size of the sample and its geographical scope. We suggest that other studies with a larger sample size and greater diversity may be useful in the creation of new knowledge to allow a more detailed evaluation of the use of telecare among the elderly.

\section{REFERENCES}

1. Liposcki DB, Andreis LM, Silva SA, Rosa Neto F. Aptidão motora de idosos longevos - implicações cognitivas e socioemocionais. Rev Kairós. 2016;19(22):227-39.

2. Rodríguez LG, Castro ST, Ramírez DM, Robledo LMG, Cuevas RP. Tele-asistencia y tele-alarma para adultos mayores: experiencias preliminares en México. Rev Saúde Pública. 2013;47(4):711-7.

3. Peeters JM, Veer AJE, Hoek LVD, Francke AL. Factors influencing the adoption of home telecare by elderly or chronically ill people: a national survey. J Clin Nurs. 2012;21(21-22):3183-93.

4. Aceros JC, Cavalcante MTL, Domènech M. Identidad de lugar en usuarios de teleasistencia: un análisis conversacional. Rev Latinoam Psicol. 2013;45(1):80-4.

5. Celich KLS, Creutzberg M, Goldim JR, Gomes I. Aging with quality of life: the perception of elderly people participating in social groups. Rev Min Enferm. 2010;14(2):226-32.

6. Carretta MB, Bettinelli LA, Erdmann AL. Reflections on nursing care and the autonomy of the human being in hospitalized. Rev Bras Enferm. 2011;64(5):958-62.

7. Neri AL. Palavras-chave em gerontologia. 4. ed. Campinas: Alínea; 2014.

\section{CONCLUSION}

The elderly using telecare had a sociodemographic profile similar to that of the elderly population, with a higher percentage of women; a mean age of 82.24 years, ranging from 60 to 94 years, evidencing their longevity. The majority were widowed and lived alone.

The decision-making process associated with the use of assistive technology involved a low perception of coercion in almost all the participants of the research, demonstrating that the elderly remain autonomous in deciding about the management of their choices. The elderly had high confidence and satisfaction regarding the use of telecare. These results allow us to state that in the studied sample the use of this technology brings benefits, since in all variables evaluated the results were favorable.
8. Cunha JXP, Oliveira JB, Nery VAS, Sena ELS, Boery RNSO, Yarid SD. Autonomy of the elderly and its ethical implications on nursing care. Saúde Debate. 2012;36(95):657-64.

9. Piaget J. Les trois systèmes de la pensée de l'enfant; étude sur les rapports de la pensée rationelle et de l'inteligence motrice. Bull Soc Fr Philos. 1928:121-2.

10. Gardner W. Factual sources of psychiatric patients' perceptions of coercion in the Hospital Admission Process. Am J Psychiatry. 1998;155:1254-60.

11. Taborda JGV. Percepção de coerção em pacientes psiquiátricos, cirúrgicos e clínicos hospitalizados [tese]. Porto Alegre: Universidade Federal do Rio Grande do Sul; 2002.

12. Jahan S. Human Development Report 2016. Geneve: UNDP; 2017.

13. Souza JR. Risco, desconhecimento e incerteza em procedimento assistencial diagnóstico em idosos [Dissertação]. Porto Alegre: Pontifícia Universidade Católica do Rio Grande do Sul; 2005.

14. Wettstein MF. Bioética e restrições alimentares por motivações religiosas: tomada de decisão em tratamentos de saúde [Dissertação]. Porto Alegre: Universidade Federal do Rio Grande do Sul; 2010.

15. Mirandola AR, Bós AJG. Relation between functional capacity and capacity of decision-making in longlived. PAJAR. 2015;3(2):53-9. 
16. Wiesiolek CC, Foss MP, Diniz PRB. Normal aging and decision-making: a systematic review of the literature of the last 10 years. J Bras Psiquiatr. 2014;63(3):255-9.

17. Wagner GP, Parente MAMP. O desempenho de idosos quanto a tomada de decisão em duas variações do Iowa Gambling Test. Psicol Teor Pesqui. 2009;25(3):425-33.
18. Wittmann-Vieira R, Goldim JR. Bioética e cuidados paliativos: tomada de decisões e qualidade de vida. Acta Paul Enferm. 2012;25(3):334-9.

19. Raymundo MM, Goldim JR. Moral-psychological development related to the capacity of adolescents and elderly patients to consent. J Med Ethics. 2008;34(8):602-5.

Received: December 14, 2017

Reviewed: May 02, 2018

Accepted: May 25, 2018 